\title{
Meaning Making Through e-Learning
}

\author{
J. Sánchez and J. Miranda \\ C5, Department of Computer Science, University of Chile \\ Blanco Encalada 2120, Santiago, Chile \\ jsanchez@dcc.uchile.cl,jmiranda@.c5.cl
}

\begin{abstract}
Different approaches have been proposed to add more educational value to e-Learning. One of these views proposes modern pedagogical models that better fit the nature of the unique features of technology. A related approach is to embed modern learning and instructional design theory into new communication and interaction channels provided by information and communication technologies such as the Internet. This study presents a model for e-Learning illustrated with a specific case study of in-service teacher training in learning with digital media. After presenting the model we describe the design, implementation, and evaluation of an e-Learning program for school teachers that uses our model. We highlight the way teachers construct meaning by reflecting on teaching and learning. Intact e-communities were developed through interaction and communication by using Internet services to share meaning, views, and understanding. Thus meaning was constructed from teachers to be used during everyday school pedagogical practices.
\end{abstract}

\section{Introduction}

Diverse approaches have been offered to add more educational value to distance learning programs. Many e-Learning programs emphasize the " $\mathrm{e}$ " side, centering on the learning management system used and searching for new tools to "improve" distance learning [3].

Even though these views are necessary we believe that the central focus is somehow missed. Very few studies concerning pedagogical models for distance learning to fit the particular and unique features of the Internet are proposed. Most programs follow a chalk and talk way of teaching without paying much attention to innovation by designing new pedagogical models to fit the unique features of new 
media [5] [7] [20]. We can summarize this vision as the "old wine in new bottle" view.

Other studies identify learning management systems as key tools that define the learning methodology and strategies. The software framework forces a way of teaching that reduces the flexibility required by active learning methodologies [3] [17] [15]. Many of them end with a model tailored to the technological framework used instead of a software framework built upon the needs and features given by the pedagogical model assumed.

Some authors have proposed innovative methods and learning strategies for eLearning [3] [2] [4] [10] [13] [14] [9] [11]. The emphasis of these innovations is on learning and centered on learners by including ways of fostering different modes of knowledge representation. They design a virtual space to construct knowledge and collaborative learning strategies supported by learning management systems.

As a result, we can end up with some e-Learning principles that support any course implementation, such as: to promote an active role of learners in the construction of knowledge, to promote meaningful learning, to promote broad and deep learning, to develop skills, attitudes and values, to allow real experiences through real world activities, to promote collaborative learning, to promote a changing role of teachers/tutors as learning facilitators, to involve learners as coevaluators, to make learners to reflect on what is doing, to use technology to enrich learning, to enhance action on knowledge objects, and to solve cognitive conflicts.

These principles emerge from underlying theories and models of learning such as constructivism, understanding as thinking, understanding as a network, social interaction, social distribution, situated learning, generalized learning, and selfregulated learning [1] [8] [17].

This study introduces a model for e-Learning that is built upon these principles, models, and theories. We describe the design, implementation, and evaluation of an e-Learning program. Our pedagogical model is illustrated with a pilot implementation with teachers. We highlight the way teachers construct meaning by reflecting on teaching and learning.

\section{Design}

We designed a whole e-Learning training program for teachers. We wanted to preserve academic quality and innovate the way we deliver education, both the technology and the model of learning. To do this we followed these steps:

Technology evaluation: We selected a learning management system and evaluated the technical requirements.

Team organization: We created a multidisciplinary team to implement the eLearning program with engineers, educators, and educational computing specialists.

Model of learning: Once we knew the characteristics of the LMS and content we designed a pedagogical model for e-Learning.

Pilot testing: We designed a pilot testing course on methodologies for using information technologies with a reduced number of teachers. We tested the functioning of the LMS and the pedagogical model. We also evaluated diverse 
materials, working interfaces, learning strategies, type of interactions, and time spent in different sections of the course.

Modeling: We designed and implemented the structure of the LMS by considering the learning model and the structure of the course program. The content of eight courses was modeled. Most of this content was already in digital format, facilitating the process content modeling.

Online classes: The students were selected and registered. Then the first week they inspected the platform by following an entrance module. Students also started to virtually communicate and know each other.

Online modules: To enhance the interaction between learners in each course we designed modules with individual and team activities to design products weekly. They used different interaction tools such as chat and forums to do collective designs and constructions.

Face-to-face modules: We designed three out of eight course modules to be delivered face-to-face. They included content that requires more student-facilitator interaction. Each course was delivered in an intensive week with a day topic and collective works.

Evaluation: We finally evaluated the courses through questionnaires and opinion polls to get ideas, comments, and suggestions concerning online and face-to-face classes. We also implemented a focus group with professors and tutors of the course to analyze and discuss the attainment of goals and objectives.

\subsection{A model for e-Learning}

Our model [18] is based on constructivist principles of learning [9] [16]. We view learning as the process of construction and modification of cognitive structures through learning by experience and collaboration. Each module of the learning cycle is oriented to obtain contextualized meaningful learning. Learners are required to reflect, apply, criticize, argument, and solve problems, thus allowing them to construct their own representations. We identify five major processes in e-Learning: realizing, approaching, conceptualizing, structuring, and applying.

Realizing consists of identifying the educational challenge. This process consists of orienting learners in their studies by identifying the problem and making their point of view. They also understand the objectives of the course work proposed and the starting points. They know what they will learn and the reason why the activities are proposed. The learner has to make representations of the expected products and results, and the rationale for doing this. Realizing involves the process of motivating, problem identification, and pre-concept/concept contrasting.

Approaching consists of constructing a new learning plan and point of view by learners, guided by a group of professionals, by designing diverse methodological proposals to fit their cognitive styles. The idea is to produce a cognitive conflict to question the learner's intuitive models and to identify the strengths of the proposed models. It involves the process of reflecting, retention, adapting, exploring, and researching. 


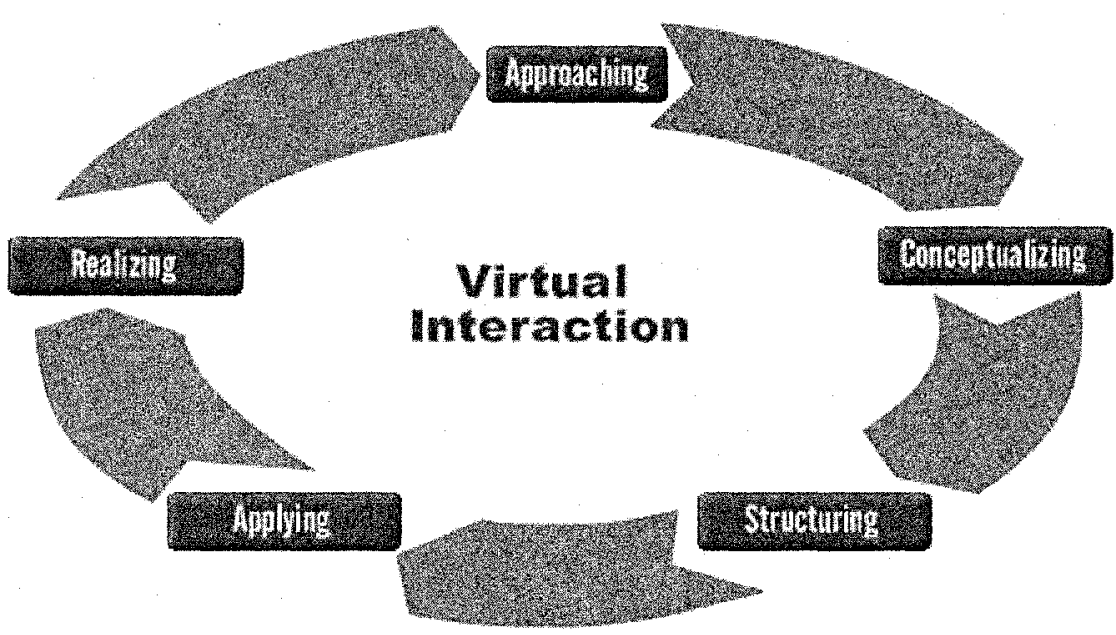

Figure 1. A model for e-Learning

Conceptualizing involves identifying the concepts and possible conceptual changes when exploring and approaching the content. It involves the processes of metacognition, representation, and adaptation.

Structuring refers to constructing meaning through didactic strategies such as synthesis, monitoring, and metacognition. This involves processes such as analysis, synthesis, retention, metacognition, and abstraction.

Applying consists of giving the opportunity to students to apply their conceptions to new and different scenarios. It involves evaluation, imaging, adaptation, abstraction, problem solving, contextualizing, and metacognition.

Virtual interaction triggers a synergetic effect on the model by carrying these five processes of knowledge efficiently and thus allowing feedback, confronting ideas, discovering, and collaboration. All these processes are critical in the construction of meaning.

\subsection{Training teachers through e-Learning}

Our center implemented an e-Learning experience in order to design and evaluate the proposed methodological learning model. We also wanted to evaluate the learning management system used and to identify main components and strategies to implement an e-Learning course. Another experience applying a former version of this model with Chilean teachers has been described in the literature [19]. 


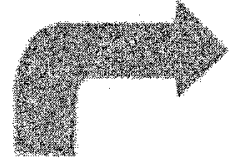

\section{Applying}

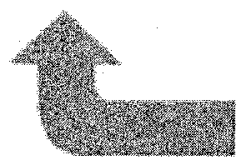

\section{Entering}

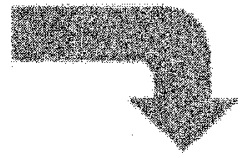

\section{Virtual interaction}

\section{Analyzing}

\section{Negotiating}

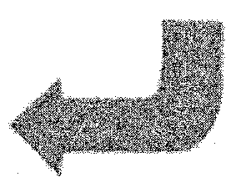

Figure 2. e-Learning cycle

In order to do this we followed five phases: Design, implementation, evaluation, feedback, and redesign. The design of the e-Learning cycle involved processes such as entering a content unit, analyzing documents, negotiating meaning, and applying what learners have learned through collaborative constructing to end with a group synthesis (see Figure 2).

To illustrate the feasibility of the model we describe the implementation of a course on methodologies for using technology for teachers (see Figure 3). Thirtyfive experienced teachers took the online course. We divided the course into eight working units with the corresponding learning activity and questions to enrich interaction among learners participating within the virtual dialog classroom. Each unit was covered in one week and ended with a synthesis of conversations, analysis, discussions, and exchanges.

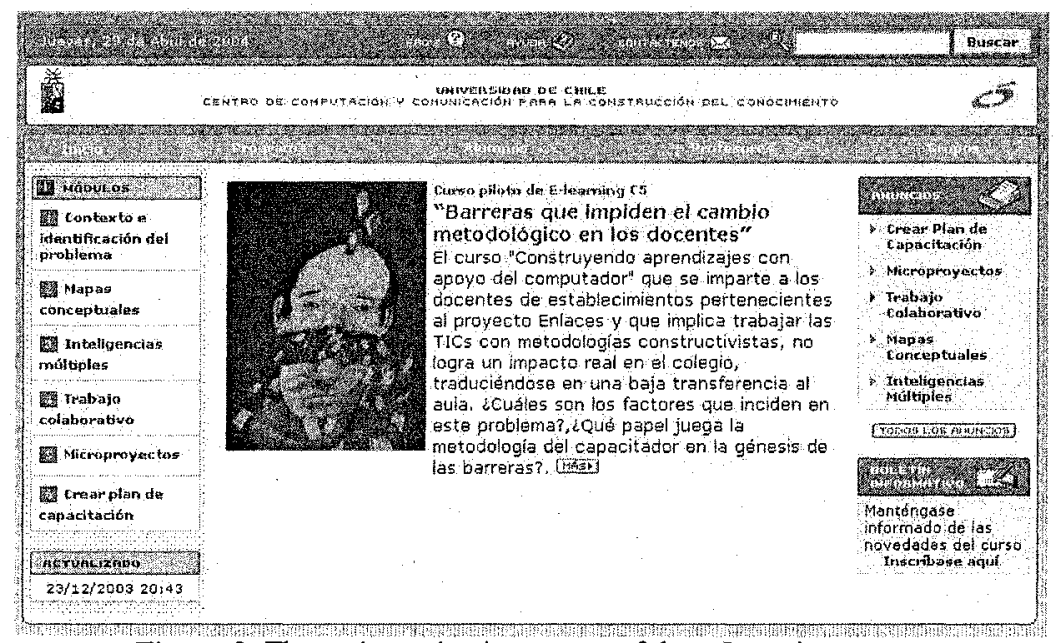

Figure 3. The main navigation screen of the e-Learning course 
Each unit was based on seven sections: 1. Unit description, 2. Mandatory documents, 3. Complementary documents, 4. Related links, 5. Activities, 6. Virtual dialog classroom, and 7. The learner's synthesis (see Figure 4 ).

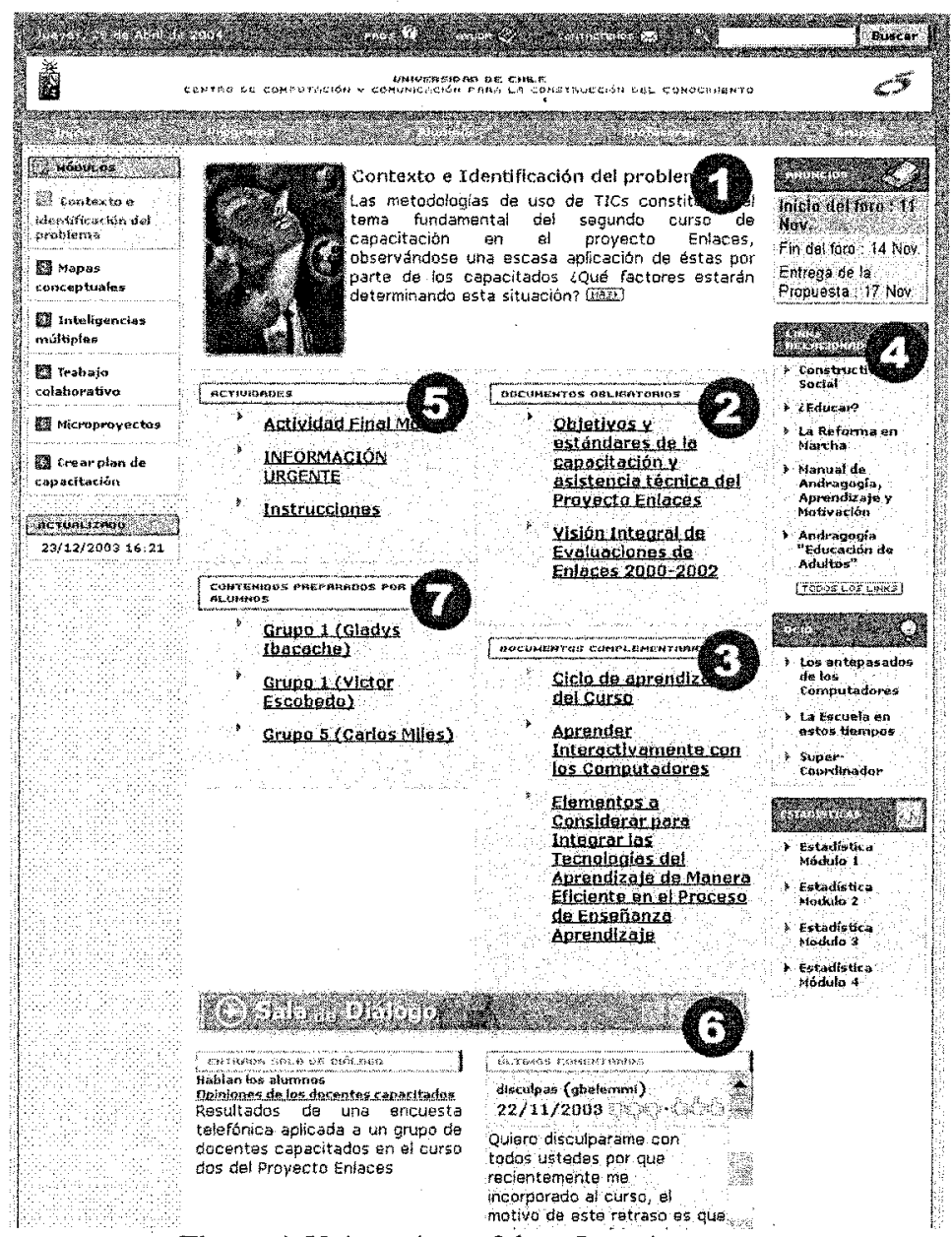

Figure 4. Unit sections of the e-Learning course

We have created an interactive virtual space for each content unit to integrate the construction of knowledge around a topic. Due to the fact that the quality of the interaction among learners was not tacit we implemented an initial strategy to break the initial barriers to communicate and interact. Learners had to introduce themselves to the class by highlighting personal strengths in a playful way and listing their expectations for the course.

As a result, we evaluated the learning management system used (www.newtenberg.cl). It was a Chilean commercial system that was modified, extended, and adapted to our pedagogical goals. The level of interaction and communication among learners was very high, more than what we have observed in 
a similar content course delivered face-to-face. Due to our emphasis on group interaction we observed that learners wanted to have individual experiences that were not provided by our learning management system. This led us to suggest a balance between individual and group experiences for e-Learning courses.

We identified some key aspects to implementing e-Learning courses for teachers. The time of the experience is very important. Courses such as the one we are presenting should concentrate on time issues when the teacher's work load is high. The time spent by students is a key to retaining them in the class. The role played by facilitators is very important to foster participation and knowledge construction. The learning management system used can determine the type of activities to be implemented but not necessarily the learning model involved. The follow-up strategy is also relevant to the e-Learning experience. Facilitators and administrators should have tools to visualize learners' actions within the virtual environment. We also think that the time period dedicated to tutoring and coordination can determine the quality of the learning experience in online courses. This means time for solving problems, follow up, and to create a working climate to motivate students to actively participate in the learning process.

\section{Methodological strategies}

Each online course was divided into five working units during six weeks with a final evaluation. Units were developed on a one-week basis and ended with an individual or collective product. The last week was dedicated to preparing and taking the final evaluation. Each unit consisted of unit description, objectives, general directions, activities, support materials, web links, and online discussions around each activity and working document.

During each module students were involved in activities such as document synthesis, term glossary, abstracts, graphic representations (schemes, concept maps), collective constructions of documents, comparative charts, and case studies.

Each course consisted of a virtual class section, synchronic communication with the professor responsible for the course and diverse discussion forums to implement activities and documents. A professor was in charge of the course, assisted by a coordinator and a teaching assistant facilitator.

\section{Meaning making through virtual interaction}

We based our observation on meaning construction when learners were interacting within the virtual dialog classroom. Two processes can occur: presenting and comparing. Presenting involves posing an opinion, comment, information or knowledge. Comparing includes contrasting beliefs and personal knowledge with other learners by verifying agreements and disagreements.

This implies three other processes: falsifying, complementing, and discovering. Falsifying means to assign falsity and error to comments and judgments as a result of disappointment with a belief, comment or knowledge idea. Complementing means that we agree with the comment and accept it as a truth but we believe that it is 
incomplete. Discovering is new knowledge for learning in terms of new ways of viewing known knowledge. These processes are grouped within the most general process of comparing and can be externalized or just mentally processed without explicating it.

The idea with our study was to go further than just presenting information. We foster discussions where personal knowledge is proof tested because of the collective interaction ending with collaborative social knowledge construction. If we wish to evaluate these processes as triggers for meaningful learning, we observe a direct relationship between previous knowledge and the quality of the construction of knowledge. Thus the more knowledge a teacher may have on a specific topic, the more probability of falsifying. This is very relevant when assigning a role to content and support materials for the virtual dialog classroom.

\section{Discussion}

The main goal of this study was to develop a model for e-Learning and test it with a group of teachers by using modern learning theories and principles that better fit eLearning.

Some of the premises of our design were the enormous potential of collaborative work and virtual interaction in e-Learning as it is mentioned in the literature. However, these learning strategies are not tacit. Even though they can facilitate learning they can also impede it. To ameliorate this there are some strategies such as teachers sharing their interests in teams and maintaining informal communication during the course work. This promotes confidence among students and group interaction around academic tasks.

One of the key aspects of facilitating collaboration was solving educational problems. Teachers could discuss themes based on their everyday experience by connecting theory and practice, and by taking into consideration the teacher's knowledge. A balanced mixture between individual and collaborative strategies is also recommended. E-Learning programs should exploit the unique capabilities of the Internet as a communication medium by going further than just student-teacher communication and emphasizing group work among students.

We believe that distance learning programs should exploit the unique features and added value of a powerful medium such as the Internet. Thus some constructivist theories and principles can be embedded into virtual environments to promote active learning and the construction of meaning.

We have presented an e-Learning model and described the design, implementation, and evaluation of a training program for school teachers. We analyzed the teacher's construction of knowledge by reflecting on teaching and learning. Through interacting and communicating we have developed electronic communities around pedagogical content. We believe that this experience reflects a way of knowledge construction from teachers that is not exclusive to e-Learning; rather, it can be used in a meaningful way during everyday pedagogical practices in the school. 


\section{References}

1. Collis, B. (1997). Pedagogical reengineering: A Pedagogical approach to course enrichment and redesign with the WWW. Educational Technology Review, 8, 11-15.

2. Dillenbourg, P. (2000). Virtual learning environments. Proceedings of EUN Conference 2000, Learning in the New Millennium: Building New Education Strategies for Schools. Workshop on Virtual Learning Environments. Geneva.

3. Garrison, D. \& Anderson, T. (2003). E-Learning in the $21^{\text {st }}$ Century: A Framework for Research and Practice. New York: Routledge/Falmer.

4. Haddad, W. (2003). Is instructional technology a must for learning?. TechKnowLogia, 56, January -March.

5. Haavind, S. (2000). Why don't face-to-face teaching strategies work in the virtual classroom? How to avoid the Question Mill. http://www.concord.org/library/2000fall/face2face.html

6. Harasim, L., S. R. Hiltz, L. Teles, and M. Turoff. (1995). Learning networks. Cambridge, MA: MIT Press.

7. Harasim, L. (1990). (Ed.). Online Education: Perspectives on a New Environment. New York: Praeger.

8. Jonassen, D. (1998). The Computer as Mindtools. TechTrends, 43(2), 24-32, March.

9. Jonassen, D. (1995). Constructivism and computer-mediated communications in distance education. The American Journal of Distance Education, 9(2), 7-26.

10. Kante, C., \& Savani, V. (2003). e-Learning, The new frontier in the developing world. TechKnowLogia, 15-19, January-March.

11. Kozma, R., Zucker, A. Espinoza, C., McGhee, R., Yarnall, L., Zalles, D., and Lesis, A. (2000). The online course experience: Evaluation of virtual high school's Third Year of Implementation, 1999-2000 Final Report, http://vhs.concord.org/Pages/About+Usproject+Evaluation

12. MacRobbie, C. \& Tobin, K. (1997). A social constructivist perspective on learning environments. International Journal of Science Education, 19, 193-208.

13. Meyen, E. L., Aust, R.J., Gauch, J.M., Hinton, H.S., Isaacson, R.E., Smith, S.J., Tee, M.Y. (2002). e-Learning: A Programmatic Research Construct for the Future. Journal of Special Education Technology, 17(3), 37-46. http://jset.unlv.edu/17.3/smith/smith.pdf

14. Pitt, T. \& Clark, A. (1998). Creating powerful online courses using multiple instructional strategies. Unpublished Manuscript, University of Colorado, Denver.

15. Salomon, G. (1988). Novel constructivist learning environments and novel technologies: Some issues to be concerned with. Research Dialogue in Learning and Instruction, (1), 1, $3-12$.

16. Sánchez, J. (2001). Visible Learning, Invisible Technology. Santiago: Dolmen Editions.

17. Sánchez, J. (2003). Learning Strategies for Distance Programs: More of the Same or a Niche for Innovation. Proceedings of the 4th APRU Distance Learning and the Internet Conference 2003, Singapore, November 30 - December 02, 2003.

18. Sánchez, J., Miranda, J. \& Vera, F. (2004a). Knowledge Construction through Virtual Interaction. To be published in the Proceedings of World Conference on 
e-Learning in Corporate, Government, Healthcare, \& Higher Education, E-Learn 2004. November 1-5. Washington DC, USA.

19. Sánchez, J., Miranda, F. \& Vera, F. (2004b). e-Learning for teachers: A Chilean experience. Proceedings of the Distance Learning and Internet Conference, APRUNet, Beijing, China, October 12-14, p.7.

20. Tinker, R. \& Haavind, S. (1996). Netcourses and Netseminars: Current Practice and New Designs. The Journal of Science Education and Technology. New York and London: Plenum Press. 